\title{
Association of rs6982567 near GDF6 with neovascular age-related macular degeneration and polypoidal choroidal vasculopathy in a Han Chinese cohort
}

\author{
Yuying Ji, Xiongze Zhang, Kunfang Wu, Yu Su, Meng Li, Chengguo Zuo and Feng Wen*
}

\begin{abstract}
Background: Growth differentiation factor 6 (GDF6) has been reported to be a novel disease gene for age-related macular degeneration (AMD) in Caucasians. This study aimed to investigate whether rs6982567 was associated with neovascular AMD (nAMD) or polypoidal choroidal vasculopathy (PCV) in a Han Chinese cohort.

Methods: A total of 612 participants (251 PCV patients, 157 nAMD patients and 204 controls) were included in this study. The SNaPshot system was used to genotype the rs6982567. PLINK software was used to evaluate the genotypes and allele frequencies of patients and controls.

Results: The allele frequencies of rs6982567 were not significantly associated with nAMD, PCV or PCV and nAMD combined. Subjects with the $\Pi$ genotype had a 2.42-fold greater risk of PCV (95\% confidence interval, 1.07-5.43, $p=0.0290$ ) than subjects with CC genotype. A recessive model of $\mathrm{r} 56982567$ was statistically significantly associated with PCV (odds ratio, 2.29; 95\% confidence interval, 1.04-5.05; $p=0.0351$ ). However, the association did not withstand stringent Bonferroni correction. There were no significant differences in genotype distributions or models in nAMD.

Conclusions: There was a possible weak association between the rs6982567 near GDF6 and PCV in this replication study with an independent Han Chinese cohort. A complete survey of the GDF6 locus with a larger sample size is needed in future studies.
\end{abstract}

Keywords: Han Chinese population, Neovascular age-related macular degeneration, Polypoidal choroidal vasculopathy, Polymorphisms, Growth differentiation factor 6

\section{Background}

Age-related macular degeneration (AMD) is a major cause of irreversible blindness around the world [1]. Neovascular AMD (nAMD) is one process of advanced AMD, characterised by typical choroidal neovascularisation $(\mathrm{CNV})$ that can cause severe vision loss [2]. Polypoidal choroidal vasculopathy $(\mathrm{PCV})$ is an exudative maculopathy marked by branching networks of inner choroidal vessels and a nodular appearance on stereoscopic view with indocyanine green angiography (ICGA) [3]. Emerging evidence has shown that PCV is more common in Asians than in Caucasians $[4,5]$, and it has been recognised as a special

\footnotetext{
* Correspondence: wenfeng208@foxmail.com

State Key Laboratory of Ophthalmology, Zhongshan Ophthalmic Center, Sun Yat-sen University, 54 South Xianlie Road, Guangzhou 510060, China
}

type of CNV [6,7]. However, the prevalence, clinical features and treatment guidelines are somewhat different. Although nAMD and PCV share some common genetic determinants, such as the complement factor $H$ gene $(C F H)$ and the high temperature requirement factor A1 (HTRA1) gene [8,9], they are not the same. For example, superkiller viralicidic activity 2-like (SKIV2 L), in the entire $C 2$ (complement component 2)-CFB (complement factor B)-RDBP (RD RNA-binding protein)$S K I V 2 L$ region, is associated with nAMD but not with PCV [10]. The rs5882 near cholesteryl ester transfer protein (CETP) is significantly associated with $\mathrm{PCV}$ but not with nAMD [11].

Growth differentiation factor 6 (GDF6) is a member of transforming growth factor- $\beta$ (TGF- $\beta$ ) superfamily. It can 
control eye development by regulating neural and vascular development $[12,13]$ and can regulate ectoderm patterning [14]. It also plays a role in tissue modelling and remodelling [15]. Recently, a study in a Caucasian cohort identified that a single nucleotide polymorphism (SNP) rs6982567 near GDF6 was associated with AMD [16]. Given that early $A M D$, advanced AMD, and PCV were not distinguished in this study, and no research about this SNP has been undertaken in Chinese populations, we conducted this study to determine whether rs6982567 was associated with nAMD and PCV in a Han Chinese population.

\section{Methods}

The study followed the tenets of the Declaration of Helsinki, and the protocol was approved by the institutional review board at the Zhongshan Ophthalmic Center of Sun Yat-sen University (lot number: KYNL015). All of the participants signed written informed consent forms after explanation of the purpose and process of the study.

\section{Study participants}

All of the participants were enrolled from Zhongshan Ophthalmic Center from November 2008 to July 2011. They were all Chinese and were not related to each other. All of the PCV and nAMD patients were newly diagnosed and received no prior treatment. They all underwent bilateral ocular examinations, including best-corrected visual acuity, slit-lamp biomicroscopy, direct ophthalmoscopy, colour fundus photographs, fundus fluorescein angiography (FFA), and ICGA. Diagnosis was made according to the worse eye. PCV was defined as characteristic polypoidal choroidal vascular dilations with branching inner choroidal vascular networks within the first 5 min after indocyanine green injection on ICGA. Typical CNV, observed on both FFA and ICGA, was diagnosed as nAMD. The exclusion criteria included combination with any retinal or choroidal diseases in one or both eyes or other neovascularised maculopathies, such as pathologic myopia, angioid streaks, idiopathic CNV, multifocal choroiditis, et al.

The control subjects were unrelated people aged $\geq$ 50 years old without family histories of AMD. They all underwent ocular examinations, including visual acuity, slit-lamp biomicroscopy, direct ophthalmoscopy and 50 degree fundus photography. Cases with any macular degeneration or changes, such as drusen, pigment abnormalities, or non-clear media preventing macular visualization, were excluded from the study.

\section{SNP genotyping}

Antecubital vein peripheral blood samples were obtained from all of the participants and were placed in tubes containing ethylene diamine tetraacetic acid. As previously described [17], genomic DNA was isolated from peripheral blood samples using the Nucleospin_Blood XL kit (Machery-Nagal GmbH\& Co., KG Düren, Germany), and it was stored at $-20^{\circ} \mathrm{C}$. Rs6982567 variants were genotyped using the SNaPshot System with an ABI 3730XL genetic analyser (Applied Biosystems, Foster City, CA, USA). The primer sequences were 5'- CATGAAATATC ATCCACAGACAA-3' (forward) and 5'- TCATTCAGT ATATGCTCCTTAG-3' (reverse), and the extension primer was TTTTTTTTTTTTTTGATTTTTTCCACATGTA GTCCT. Genemapper software, version 4.1(Applied Biosystems, Foster City, CA, USA), was used to determine the genotypes of the SNP.

\section{Statistics}

Statistical analysis was performed using SPSS software, version 13.0 (SPSS Inc., Chicago, IL, USA). Student's unpaired $t$-test and the chi-square test were used to assess the differences in mean age and sex between the subjects and controls. A p value $<0.05$ was considered statistically significant. The exact test included in the PLINK software package, version 1.07, was used to test the deviations from Hardy-Weinberg equilibrium [18]. The chi-square test in PLINK was used to determine the allele frequencies of the SNPs in the case subjects. To assume the genotypic additive model, dominant and recessive model, the logistic option and model option in PLINK were used, respectively. Bonferroni's method was performed to correct the $\mathrm{p}$ values in multiple comparisons, with a $\mathrm{p}$ value $<0.0056$ $(0.05 \div 3 \div 3)$ considered to be statistically significant. $G^{*}$ Power software, version 3.1.10, was used to evaluate the post-hoc power [19].

Table 1 The clinical characteristics of the participants

\begin{tabular}{|c|c|c|c|c|c|}
\hline Characteristics & PCV & nAMD & Control & p value* & $p$ value \\
\hline Number (n) & 251 & 157 & 204 & & \\
\hline Gender (female/male) & $84 / 167$ & $56 / 101$ & $80 / 124$ & 0.204 & 0.488 \\
\hline Mean age $\pm S D$ years & $65 \pm 8.61$ & $67 \pm 9.21$ & $69 \pm 9.00$ & $<0.001$ & 0.097 \\
\hline Age ranges (years) & $42-85$ & $46-84$ & $50-87$ & & \\
\hline
\end{tabular}

PCV: polypoidal choroidal vasculopathy.

nAMD: neovascular age-related macular degeneration.

*: PCV group compared with control group.

${ }^{\dagger}$ : nAMD group compared with control group. 
Table 2 The association test for the minor allele frequency of rs6982567

\begin{tabular}{ccccc}
\hline Status & HWE & MAF & OR $(\mathbf{9 5} \% \mathbf{C l})$ & p value \\
\hline Control & 0.1016 & 0.2623 & & \\
PCV & 0.2555 & 0.2912 & $1.29(0.97-1.73)$ & 0.0832 \\
nAMD & 0.5798 & 0.2548 & $0.91(0.65-1.28)$ & 0.6029 \\
PCV + nAMD & 0.6167 & 0.2794 & $1.14(0.87-1.49)$ & 0.3444 \\
\hline
\end{tabular}

SNP: single nucleotide polymorphism.

PCV: polypoidal choroidal vasculopathy.

nAMD: neovascular age-related macular degeneration.

MAF: minor allele frequency.

HWE: $p$ value of Hardy-Weinberg equilibrium test.

OR: odds ratio.

95\% Cl: 95\% confidence interval.

Minor allele frequencies were calculated based on all study participants.

\section{Results}

A total of 612 participants were enrolled: $251 \mathrm{PCV}$ patients, 157 nAMD patients and 204 control individuals. Table 1 showed the clinical baseline characteristics. The mean age of the PCV group ( $65 \pm 8.61$ years) was younger than the control group, and the difference was significant $(p<0.001)$. There were no significant differences in other characteristics, such as sex among the three groups.

For the quality assurance of our samples, the genotyping call rates were $100 \%$ for rs6958967 in both the patient and control groups. The genotypes were determined using the SNaPshot method successfully in all of the subjects. To confirm the accuracy of the SNaPshot method, randomly selected subjects ( $10 \%$ of all samples) were analysed by direct sequencing. The consensus rate in the replicate samples $(n=61)$ was $100 \%$. The results of Hardy-Weinberg equilibrium (HWE) analysis showed no significant deviation in rs6982567, as shown in Table 2. The allele frequencies of rs6982567 were not significantly associated with nAMD, PCV or PCV and nAMD combined. The frequencies of the $\mathrm{T}$ allele were $29.12 \%$ for
PCV, 25.48\% for nAMD, and 27.94\% for PCV and nAMD combined. The odds ratio (OR) for the risk allele $\mathrm{T}$ of rs6982567 was 1.29 for PCV [95\% confidence interval (CI), 0.97-1.73, $\mathrm{p}=0.0832$ ], 0.91 for nAMD (95\% CI, 0.65-1.28, $\mathrm{p}=0.6029)$, and 1.14 for PCV and nAMD combined $(95 \%$ $\mathrm{CI}, 0.87-1.49, \mathrm{p}=0.3444$ ).

The genotype association test of rs6982567 was summarised in Table 3. Subjects with the TT genotype had a 2.42-fold times greater risk of PCV (95\% CI, 1.07-5.43, $\mathrm{p}=0.0290)$ than subjects with the CC genotype. The variant was significantly associated with PCV under a recessive model (OR, 2.29; 95\% CI, 1.04-5.05; $\mathrm{p}=0.0351$ ). However, after Bonferroni correction, the $\mathrm{p}$ value was insignificant $(p>0.0056)$. The genotype distributions and additive, dominant and recessive models were not significantly associated with nAMD (all p values $>0.05$ ). Combining PCV with nAMD as a group, the genotype distributions and additive and dominant models also showed no significant differences (all $\mathrm{p}$ values $>0.05$ ). Although there was a marginal association under a recessive model in the PCV and nAMD combined group ( $\mathrm{p}=0.0487$ ), it could not withstand the Bonferroni correction ( $\mathrm{p}>0.0056$ ).

The present sample size showed $>80 \%$ power to detect significant association for power calculations $(\alpha<0.017)$, and the effect size of 0.2 corresponded to a weak-tomoderate gene effect. When comparing patients to controls, the allele powers for PCV and nAMD were $97.00 \%$ and $92.12 \%$, respectively, and the genotype powers for PCV and nAMD were $94.01 \%$ and $86.42 \%$, respectively.

\section{Discussion}

Both PCV and nAMD are most common causes of irreversible visual impairment in older people worldwide. The exact pathogenesis remains unknown, and the complex genetic backgrounds remain under exploration. In this

Table 3 The association test for the genotype of rs6982567

\begin{tabular}{|c|c|c|c|c|c|c|}
\hline \multirow[b]{2}{*}{ Group } & \multirow[b]{2}{*}{ Genotype } & \multicolumn{3}{|c|}{ Genotype distribution } & \multicolumn{2}{|c|}{ Genotype } \\
\hline & & Case & Control & OR $(95 \% \mathrm{Cl}) \mathrm{p}$ value & Model & OR $(95 \% \mathrm{Cl}) \mathrm{p}$ value \\
\hline \multirow[t]{3}{*}{ PCV } & $\mathrm{CC}$ & 117 & 106 & reference & Additive & $1.31(0.97-1.78) 0.0747$ \\
\hline & $\mathrm{TC}$ & 110 & 89 & $1.12(0.76-1.64) 0.5657$ & Dominant & $1.24(0.86-1.79) 0.2560$ \\
\hline & $\pi$ & 24 & 9 & $2.42(1.07-5.43) 0.0290$ & Recessive & $2.29(1.04-5.05) 0.0351$ \\
\hline \multirow[t]{3}{*}{ nAMD } & $\mathrm{CC}$ & 92 & 106 & reference & Additive & $0.91(0.65-1.29) 0.5961$ \\
\hline & $\mathrm{TC}$ & 53 & 89 & $0.69(0.44-1.07) 0.0931$ & Dominant & $0.76(0.50-1.16) 0.2088$ \\
\hline & $\pi$ & 12 & 9 & $1.54(0.62-3.81) 0.3510$ & Recessive & $1.79(0.74-4.37) 0.1936$ \\
\hline \multirow[t]{3}{*}{$P C V+n A M D$} & $\mathrm{CC}$ & 209 & 106 & reference & Additive & $1.14(0.87-1.50) 0.3390$ \\
\hline & $\mathrm{TC}$ & 163 & 89 & $0.93(0.66-1.32) 0.6801$ & Dominant & $1.03(0.74-1.44) 0.8625$ \\
\hline & $\pi$ & 36 & 9 & $2.03(0.94-4.37) 0.0660$ & Recessive & $2.10(0.99-4.44) 0.0487$ \\
\hline
\end{tabular}

SNP: single nucleotide polymorphism.

PCV: polypoidal choroidal vasculopathy.

nAMD: neovascular age-related macular degeneration.

OR: odds ratio; $95 \% \mathrm{Cl}$ : $95 \%$ confidence interval. 
study, we first performed rs6982567 near GDF6 genotyping in Chinese PCV and nAMD patients. The results suggested that a weak association might exist between rs6982567 near GDF6 and PCV. The marginal association under a recessive model in the PCV and nAMD combined group might be attributed to that between this SNP and the PCV group.

GDF6 belongs to the largest gene group within the TGF superfamily [20], which plays an important role in vascular angiogenesis and remodelling [21,22]. GDF6 has functions in eye and retinal development [23]. Sequence alternations in GDF6, such as amino acid substitutions, have been identified in some patients with ocular anomalies (microphthalmia, anophthalmia, coloboma) and vertebral segmentation anomalies [15,24-26]. GDF6 also participates in tissue healing and remodelling [23,27]. Wolfman N M found that, in rats, three members of TGF- $\beta$ family, GDFs 5,6 , and 7 , could induce dense connective tissue formation rich in collagen type I when implanted ectopically or intramuscularly [28]. In vitro, the GDF6 gene plays a potential role in tendon matrix modelling and remodelling $[29,30]$.

Bruch's membrane is the innermost layer of the choroid and is rich in elastin and collagen. Typical findings of PCV on ICGA include an abnormal choroidal vascular network surrounded by characteristic polyp-like dilations at the border [31]. Notable sclerotic changes in PCV lesions and an elastic layer within the walls in polypoidal vessel disruption have been found in histopathologic studies $[32,33]$. A mouse model of PCV demonstrated severe degradation of the tunica media of choroidal vessel walls and elastic laminae [34]. Our previous study had found that circulating gelatinase levels were elevated in $\mathrm{PCV}$ patients but not in nAMD patients, providing evidence of a role of extracellular matrix metabolism in the pathogenesis of PCV [35]. Considering GDF6's role in retinal development and tendon tissue function, mutations of GDF6 could result in dysfunction of vascular and supporting tissues, thus participating in the pathogenesis of PCV.

A previous study in Caucasians showed that the rs6982567 variant was associated with AMD [16]. There were two primary reasons for the inconsistency. First, the inclusion criteria were not the same. In the Caucasian study, the patients were classified according to the AgeRelated Eye Disease Study classification, which included the geographic atrophy and did not specify the diagnosis of PCV. In our study, ICGA was used to distinguish PCV from AMD. Geographic atrophy was excluded from our study. We only included neovascular AMD patients. For this reason, the types of patients were not exactly the same. Second, the study populations came from different ethnic group. The same SNP might have different distributions in different populations. The serpin peptidase inhibitor, clade G, member 1, (SERPING1) gene was reported to be associated with Caucasian populations [36], but the results were negative in Han Chinese and Japanese populations [17,37]. In the HapMap project, the allele frequencies of rs6982567 were 0.168 in Utah residents with Northern and Western European ancestry, 0.279 in Han Chinese people and 0.218 in Japanese people, exhibiting differences across ethnicities. These differences could constitute another explanation for the different outcomes.

There were also some limitations of our study. First, we conducted it in a relatively small sample, so we could not fully identify the associations between rs6982567 and PCV. Second, we only investigated a single SNP near the GDF6 gene in this study. So far, other SNPs in GDF6 locus and linkage disequilibrium (LD) analysis with this gene have yet not been completely investigated. Therefore, a complete survey of the whole target SNP in LD with the GDF6 gene with a larger sample size would be needed.

\section{Conclusions}

In conclusion, we investigated the associations of SNP rs6982567 with PCV, nAMD in a Han Chinese population. There was a marginal association between rs6982567 and PCV under a recessive model. Expanding the sample size and exploring the whole target SNPs in or near GDF6 gene are needed in future studies.

\section{Competing interests}

The authors declare that they have no competing interests.

\section{Authors' contributions}

YJ participated in the design, conduct of the study and drafted the manuscript. YJ, XZ, KW, YS, ML, CZ participated in the acquisition, analysis and interpretation of the data. $X Z, K W, Y S$ and $F W$ helped in the provision of patients. YJ, XZ and FW participated in the critical revision and final approval of the version to be published. All authors read and approved the final manuscript.

\section{Acknowledgements}

This study was supported by the National Natural Science Foundation of China (grant number: 81271011 and 81200705) and the Fundamental

Research Funds of State Key Laboratory of Ophthalmology.

The authors indicated no financial disclosures.

Received: 21 July 2014 Accepted: 11 November 2014

Published: 22 November 2014

\section{References}

1. De Jong PT: Age-related macular degeneration. N Engl J Med 2006 355:1474-1485.

2. Lim LS, Mitchell P, Seddon JM, Holz FG, Wong TY: Age-related macular degeneration. Lancet 2012, 379:1728-1738.

3. Koh AH, Chen $\sqcup$, Chen SJ, Chen Y, Giridhar A, lida T, Kim H, Yuk YLT, Lee WK, Li X, Han LT, Ruamviboonsuk P, Sharma T, Tang S, Yuzawa M: Polypoidal choroidal vasculopathy: evidence-based guidelines for clinical diagnosis and treatment. Retina 2013, 33:686-716.

4. Wen F, Chen C, Wu D, Li H: Polypoidal choroidal vasculopathy in elderly Chinese patients. Graefes Arch Clin Exp Ophthalmol 2004, 242:625-629.

5. Laude A, Cackett PD, Vithana EN, Yeo IY, Wong D, Koh AH, Wong TY, Aung T: Polypoidal choroidal vasculopathy and neovascular age-related macular degeneration: same or different disease? Prog Retin Eye Res 2010, 29:19-29.

6. Khan S, Engelbert M, Imamura Y, Freund KB: Polypoidal choroidal vasculopathy: simultaneous indocyanine green angiography and 
eye-tracked spectral domain optical coherence tomography findings. Retina 2012, 32:1057-1068.

7. Kokame GT: Polypoidal choroidal vasculopathy - a type I polypoidal subretinal neovasculopathy. Open Ophthalmol J 2013, 7:82-84.

8. Liang XY, Lai TY, Liu DT, Fan AH, Chen L, Tam PO, Chiang SW, Ng TK, Lam DS, Pang CP: Differentiation of exudative age-related macular degeneration and polypoidal choroidal vasculopathy in the ARMS2/HTRA1 locus. Invest Ophthalmol Vis Sci 2012, 53:3175-3182.

9. Chen H, Liu K, Chen L, Hou P, Chen W, Pang CP: Genetic associations in polypoidal choroidal vasculopathy: a systematic review and meta-analysis. Mol Vis 2012, 18:816-829.

10. Liu K, Chen LJ, Tam PO, Shi Y, Lai TY, Liu DT, Chiang SW, Yang M, Yang Z, Pang CP: Associations of the C2-CFB-RDBP-SKIV2L locus with age-related macular degeneration and polypoidal choroidal vasculopathy. Ophthalmology 2013, 120:837-843.

11. Zhang X, Li M, Wen F, Zuo C, Chen H, Wu K, Zeng R: Different impact of high-density lipoprotein-related genetic variants on polypoidal choroidal vasculopathy and neovascular age-related macular degeneration in a Chinese Han population. Exp Eye Res 2013, 108:16-22.

12. Asai-Coakwell M, French CR, Berry KM, Ye M, Koss R, Somerville M, Mueller R, van Heyningen $V$, Waskiewicz AJ, Lehmann OJ: GDF6, a novel locus for a spectrum of ocular developmental anomalies. Am J Hum Genet 2007, 80:306-315.

13. Hanel ML, Hensey C: Eye and neural defects associated with loss of GDF6. BMC Dev Biol 2006, 6:43.

14. Chang C, Hemmati-Brivanlou A: Xenopus GDF6, a new antagonist of noggin and a partner of BMPs. Development 1999, 126:3347-3357.

15. den Hollander Al, Biyanwila J, Kovach P, Bardakjian T, Traboulsi El, Ragge NK, Schneider A, Malicki J: Genetic defects of GDF6 in the zebrafish out of sight mutant and in human eye developmental anomalies. BMC Genet 2010, 11:102.

16. Zhang L, Lim SL, Du H, Zhang M, Kozak I, Hannum G, Wang X, Ouyang H, Hughes G, Zhao L, Zhu X, Lee C, Su Z, Zhou X, Shaw R, Geum D, Wei X, Zhu J, Ideker T, Oka C, Wang N, Yang Z, Shaw PX, Zhang K: High temperature requirement factor $A 1$ (HTRA1) gene regulates angiogenesis through transforming growth factor-beta family member growth differentiation factor 6. J Biol Chem 2012, 287:1520-1526.

17. Li M, Wen F, Zuo C, Zhang X, Chen H, Huang S, Luo G: SERPING1 polymorphisms in polypoidal choroidal vasculopathy. Mol Vis 2010, 16:231-239.

18. Purcell S, Neale B, Todd-Brown K, Thomas L, Ferreira MA, Bender D, Maller J, Sklar P, de Bakker PI, Daly MJ, Sham PC: PLINK: a tool set for whole-genome association and population-based linkage analyses. Am J Hum Genet 2007, 81:559-575.

19. Faul F, Erdfelder E, Lang AG, Buchner A: G*Power 3: a flexible statistical power analysis program for the social, behavioral, and biomedical sciences. Behav Res Methods 2007, 39:175-191.

20. Hogan BL: Bone morphogenetic proteins: multifunctional regulators of vertebrate development. Genes Dev 1996, 10:1580-1594

21. Gordon KJ, Blobe GC: Role of transforming growth factor-beta superfamily signaling pathways in human disease. Biochim Biophys Acta 2008, 1782:197-228.

22. Fritsche LG, Chen W, Schu M, Yaspan BL, Yu Y, Thorleifsson G, Zack DJ, Arakawa S, Cipriani V, Ripke S, Igo RJ, Buitendijk GH, Sim X, Weeks DE, Guymer RH, Merriam JE, Francis PJ, Hannum G, Agarwal A, Armbrecht AM, Audo I, Aung T, Barile GR, Benchaboune M, Bird AC, Bishop PN, Branham KE, Brooks M, Brucker AJ, Cade WH, et al: Seven new loci associated with age-related macular degeneration. Nat Genet 2013, 45:433-439. 431e-439e.

23. Williams LA, Bhargav D, Diwan AD: Unveiling the bmp13 enigma: redundant morphogen or crucial regulator? Int J Biol Sci 2008, 4:318-329.

24. Asai-Coakwell M, French CR, Ye M, Garcha K, Bigot K, Perera AG, StaehlingHampton K, Mema SC, Chanda B, Mushegian A, Bamforth S, Doschak MR, Li G, Dobbs MB, Giampietro PF, Brooks BP, Vijayalakshmi P, Sauve Y, Abitbol M, Sundaresan $P$, van Heyningen $V$, Pourquie O, Underhill TM, Waskiewicz AJ, Lehmann OJ: Incomplete penetrance and phenotypic variability characterize Gdf6-attributable oculo-skeletal phenotypes. Hum Mol Genet 2009, 18:1110-1121.

25. Chassaing N, Causse A, Vigouroux A, Delahaye A, Alessandri JL, BoespflugTanguy O, Boute-Benejean O, Dollfus H, Duban-Bedu B, Gilbert-Dussardier B, Giuliano F, Gonzales M, Holder-Espinasse M, Isidor B, Jacquemont ML, Lacombe D, Martin-Coignard D, Mathieu-Dramard M, Odent S, Picone O,
Pinson L, Quelin C, Sigaudy S, Toutain A, Thauvin-Robinet C, Kaplan J, Calvas P: Molecular findings and clinical data in a cohort of 150 patients with anophthalmia/microphthalmia. Clin Genet 2014, 86:326-334.

26. Gonzalez-Rodriguez J, Pelcastre EL, Tovilla-Canales JL, Garcia-Ortiz JE, Amato-Almanza M, Villanueva-Mendoza C, Espinosa-Mattar Z, Zenteno JC: Mutational screening of CHX10, GDF6, OTX2, RAX and SOX2 genes in 50 unrelated microphthalmia-anophthalmia-coloboma (MAC) spectrum cases. Br J Ophthalmol 2010, 94:1100-1104.

27. Wong YP, Fu SC, Cheuk YC, Lee KM, Wong MW, Chan KM: Bone morphogenetic protein 13 stimulates cell proliferation and production of collagen in human patellar tendon fibroblasts. Acta Orthop 2005, 76:421-427.

28. Wolfman NM, Hattersley G, Cox K, Celeste AJ, Nelson R, Yamaji N, Dube JL, DiBlasio-Smith E, Nove J, Song JJ, Wozney JM, Rosen V: Ectopic induction of tendon and ligament in rats by growth and differentiation factors 5 , 6, and 7, members of the TGF-beta gene family. J Clin Invest 1997 100:321-330.

29. Mikic B, Rossmeier K, Bierwert L: Sexual dimorphism in the effect of GDF-6 deficiency on murine tendon. J Orthop Res 2009, 27:1603-1611.

30. Haddad-Weber M, Prager P, Kunz M, Seefried L, Jakob F, Murray MM, Evans $\mathrm{CH}$, Noth U, Steinert AF: BMP12 and BMP13 gene transfer induce ligamentogenic differentiation in mesenchymal progenitor and anterior cruciate ligament cells. Cytotherapy 2010, 12:505-513.

31. Imamura Y, Engelbert M, lida T, Freund KB, Yannuzzi LA: Polypoidal choroidal vasculopathy: a review. Surv Ophthalmol 2010, 55:501-515.

32. Okubo A, Sameshima M, Uemura A, Kanda S, Ohba N: Clinicopathological correlation of polypoidal choroidal vasculopathy revealed by ultrastructural study. Br J Ophthalmol 2002, 86:1093-1098.

33. Kuroiwa S, Tateiwa H, Hisatomi T, Ishibashi T, Yoshimura N: Pathological features of surgically excised polypoidal choroidal vasculopathy membranes. Clin Experiment Ophthalmol 2004, 32:297-302.

34. Jones A, Kumar S, Zhang N, Tong Z, Yang JH, Watt C, Anderson J, Amrita, Fillerup H, McCloskey M, Luo L, Yang Z, Ambati B, Marc R, Oka C, Zhang K, Fu Y: Increased expression of multifunctional serine protease, HTRA1, in retinal pigment epithelium induces polypoidal choroidal vasculopathy in mice. Proc Natl Acad Sci U S A 2011, 108:14578-14583.

35. Zeng R, Wen F, Zhang $X$, Su Y: Serum levels of matrix metalloproteinase 2 and matrix metalloproteinase 9 elevated in polypoidal choroidal vasculopathy but not in age-related macular degeneration. Mol Vis 2013, 19:729-736.

36. Ennis S, Jomary C, Mullins R, Cree A, Chen X, Macleod A, Jones S, Collins A,

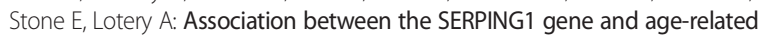
macular degeneration: a two-stage case-control study. Lancet 2008, 372:1828-1834.

37. Nakata I, Yamashiro K, Yamada R, Gotoh N, Nakanishi H, Hayashi H, Tsujikawa A, Otani A, Saito M, lida T, Oishi A, Matsuo K, Tajima K, Matsuda F, Yoshimura N: Association between the SERPING1 gene and age-related macular degeneration and polypoidal choroidal vasculopathy in Japanese. PLoS One 2011, 6:e19108.

doi:10.1186/1471-2415-14-140

Cite this article as: Ji et al.: Association of rs6982567 near GDF6 with neovascular age-related macular degeneration and polypoidal choroidal vasculopathy in a Han Chinese cohort. BMC Ophthalmology 2014 14:140.

\section{Submit your next manuscript to BioMed Central and take full advantage of:}

- Convenient online submission

- Thorough peer review

- No space constraints or color figure charges

- Immediate publication on acceptance

- Inclusion in PubMed, CAS, Scopus and Google Scholar

- Research which is freely available for redistribution 